\title{
Nutritional status and functionality in geriatric rehabilitation patients: a systematic review and meta-analysis
}

\author{
Julia Wojzischke ${ }^{1}$ - Janneke van Wijngaarden ${ }^{2} \cdot$ Claudia van den Berg $^{2} \cdot$ Aysun Cetinyurek-Yavuz $^{2}$. \\ Rebecca Diekmann ${ }^{1} \cdot$ Yvette Luiking ${ }^{2} \cdot$ Jürgen Bauer $^{3}$
}

Received: 8 November 2019 / Accepted: 20 January 2020 / Published online: 12 February 2020

(c) The Author(s) 2020

\section{Key summary points}

Aim This systematic review and meta-analysis aims to characterize the nutritional status of geriatric rehabilitation patients and its association with functional parameters.

Findings Malnutrition is prevalent in a relevant percentage of geriatric rehabilitation patients, whereas body mass index (BMI) is in the normal to overweight range. Furthermore, data suggest that protein and energy intake is reduced and vitamin $\mathrm{D}$ deficiency is prevalent in this population. Decreased physical function is associated with malnutrition according to MiniNutritional Assessment (MNA) and MNA short form, whereas BMI did not show any clear association.

Message Nutritional status is reduced in a relevant percentage of geriatric rehabilitation patients and associated with decreased physical function which emphasizes the need for screening and targeted interventions.

\begin{abstract}
Purpose Since there is only limited evidence available for geriatric rehabilitation patients, this systematic review and metaanalysis aims to characterize the nutritional status in this population and its relationship with functionality.

Methods Eight databases were searched for full-text articles reporting baseline nutritional intake and status of adults $\geq 60$ years in rehabilitation settings. Pooled estimates were calculated for prevalence of malnutrition and risk of malnutrition based on the Mini Nutritional Assessment (MNA) and for mean body mass index (BMI). Associations between nutritional status (MNA, MNA short form and BMI) and functional status (Barthel Index and Functional Independence Measure) and prevalence of sarcopenia were reviewed.

Results 62 out of 1717 references were eligible for inclusion. Pooled prevalence [95\% confidence interval (CI)] of malnutrition and risk of malnutrition were 13 (5-20) \% and 47 (40-54) \%. Pooled estimate (95\% CI) for BMI was 23.8 (23.2-24.5) $\mathrm{kg} / \mathrm{m}^{2}$. Existing data suggest a risk for low protein and energy intake and vitamin D deficiency. Functional status differed widely. Seven out of ten studies reported significant associations between reduced nutritional status and reduced functionality, whilst two out of seven studies reported significant associations between higher BMI and functionality. Prevalence of sarcopenia was high with $40-76 \%$ in this population.

Conclusions Although geriatric rehabilitation populations and settings were heterogeneous, a relevant percentage of geriatric rehabilitation patients were affected by a reduced nutritional status. Nutritional status was associated with decreased functionality. This emphasizes the need for screening for malnutrition and targeted nutritional intervention.
\end{abstract}

Keywords Geriatric rehabilitation $\cdot$ Nutritional status $\cdot$ MNA $\cdot$ BMI $\cdot$ Meta-analysis $\cdot$ Systematic review

Electronic supplementary material The online version of this article (https://doi.org/10.1007/s41999-020-00294-2) contains supplementary material, which is available to authorized users.

Julia Wojzischke

julia.wojzischke@uol.de

1 Department of Health Services Research, Carl von Ossietzky University Oldenburg, Ammerländer Heerstraße 140, 26129 Oldenburg, Germany
2 Danone Nutricia Research, Uppsalalaan 12, 3584 CT Utrecht, The Netherlands

3 Center for Geriatric Medicine, Agaplesion Bethanien Hospital Heidelberg, Geriatric Center at the Heidelberg University, Rohrbacher Straße 149, 69126 Heidelberg, Germany 


\section{Introduction}

Recent studies in older patients have illustrated the relevance of nutritional status for recovery from acute illness and functional capacity [1]. Good nutritional status allows for faster recovery from illness, shorter hospital stays and reduced rates of readmission [2]. Malnutrition and weight loss, body mass index (BMI) values lower than $20 \mathrm{~kg} / \mathrm{m}^{2}$, reduced food intake in general and reduced protein intake specifically are established independent factors which negatively influence functional parameters in older people [3, 4]. While nutritional status and its association with functionality has been well examined in community-dwelling older individuals [5-7], in older hospital patients [2, 8] and in nursing home residents $[9,10]$, only scarce information is available in geriatric rehabilitation. The majority of patients in a geriatric rehabilitation setting is significantly older than 70 years, multimorbid and has a reduced functional status, which necessitates nursing care for activities of daily living [11]. In addition, the nutrition-related diseases sarcopenia and frailty [12] are highly prevalent in this population [13, 14]. The goal of geriatric rehabilitation is to stimulate functional recovery and thereby allow patients to return to their homes $[11,15,16]$.

In general, geriatric rehabilitation consists of a structured program, which is in most countries provided by a team of physicians, nurses, physiotherapists, occupational therapists, speech therapists, psychologists, dietitians and social workers [17]. The meta-analysis of Bachmann et al. showed effectiveness of inpatient rehabilitation in older patients ( $\geq 55$ years) in a multidisciplinary rehabilitation setting with regard to the recovery of physical function [15]. However, data describing the nutritional status in detail beyond a questionnaire-based diagnosis of malnutrition are very limited in this population. Geriatric rehabilitation patients, such as hip fracture or heart failure patients are in most cases transferred from acute hospital wards and especially these patient groups have a high prevalence of malnutrition [18-20]. Profound insight into the nutritional situation of geriatric rehabilitation patients appears to be warranted, as specific nutritional interventions might help to stimulate the restoration of functional capacity in this highly vulnerable population.

The aim of the present systematic literature review and meta-analysis was to describe the nutritional status of the geriatric rehabilitation population in detail and to investigate the interrelationship between nutritional and functional outcomes.

\section{Materials and methods}

This systematic literature review was performed following the Preferred Reporting Items for Systematic reviews and Meta-analyses (PRISMA) guidelines [21, 22].

\section{Search strategy}

The literature database search was carried out in November 2016, including the following databases: Cab Abstracts, MEDLINE, EMBASE, Current Contents, Allied \& Complementary Medicine, British Nursing Index, Global Health, and PsycINFO. The search was not restricted by publication year or language. Additional references were identified by screening reference lists of narrative or systematic reviews retrieved from database search. The search string consisted of keywords describing older people, rehabilitation, nutritional status and functionality. The full search terms are shown in Online Resource 1. A search update was performed in June 2018.

\section{Selection of studies}

After removing duplicates, titles and abstracts of all records retrieved by the search process were screened independently for eligibility by two researchers (JvW and JW). The eligible groups were compared, and inconsistencies were discussed and resolved. In a second selection step, the full texts of all eligible records were screened for predefined inclusion and exclusion criteria by three researchers ( $\mathrm{CvdB}, \mathrm{JvW}$ and JW). A random cross-check (43\%) was done by a second reviewer, and discrepancies were discussed until resolved. Only fulltext articles were considered.

\section{Study population}

Studies investigating a population of older adults, aged 60 years and older attending inpatient or outpatient geriatric rehabilitation, were eligible for inclusion. Geriatric rehabilitation was defined to take place in sub-acute rehabilitation facilities for a wide range of medical conditions such as hip fracture, hip replacement, cardiac, pulmonary, stroke rehabilitation and others. Studies with participants in residential aged care facilities, in mental health facilities or drug and alcohol rehabilitation centers, in palliative care settings and studies recruiting solely cognitively impaired participants or exclusively those with dysphagia requiring a texture-modified diet were excluded. 


\section{Nutritional and functional parameters}

References were included if they reported on nutritional status parameters on admission to rehabilitation care. Eligible nutritional status parameters were not defined up front, because comparability of parameters had the highest priority. Articles were included if baseline nutritional data were present including information on malnutrition and risk of malnutrition based on established screening tools [e.g., Mini Nutritional Assessment (MNA), MNA short form (MNA-SF) and Malnutrition Universal Screening Tool (MUST)], anthropometric parameters (e.g., BMI, body circumferences and skinfold measurements), body composition parameters (e.g., fat mass, fat-free mass, muscle mass), nutrition-related blood marker (e.g., albumin, micronutrient status) as well as nutritional intake parameter (e.g., energy and protein intake). Sarcopenia status, frailty status, muscle strength parameters, parameters reflecting muscle function (e.g., mobility, gait and balance tests) and functional status parameters [e.g., Activities of Daily Living (ADL) and instrumental ADL (IADL)] were extracted if available.

\section{Type of studies}

Studies were eligible for inclusion if they were observational studies including cohort, case-control and cross-sectional studies as well as comparative studies with concurrent and non-concurrent controls. Studies with a qualitative study design and case report studies were excluded. Furthermore, studies published in languages other than English, Dutch or German were excluded for practical reasons.

\section{Data extraction}

Data extraction was performed by the three researchers $(\mathrm{CvdB}, \mathrm{JvW}, \mathrm{JW})$. Data extraction included geriatric rehabilitation patient characteristics, description of the rehabilitation setting, and baseline nutritional and functional outcomes, measured at admission to rehabilitation. Values were extracted as values for total groups when available. If an overall value of the total group was not provided in the study publication, data of subgroups were converted into a calculated weighted average for the total group. Extracted data were cross-checked in $37 \%$ of the cases to increase the quality of data extraction. Discrepancies were resolved by discussion.

\section{Statistical analysis}

For the meta-analysis, data were pooled for MNA, BMI and albumin using the rma.uni function of metafor package [23] in R (R Foundation for Statistical Computing, Vienna, Austria) [24]. For BMI and albumin, mean values were pooled.
For MNA, the percentage of subjects with malnutrition and subjects at risk of malnutrition were pooled. When the standard deviations were missing, imputation based on available publications was performed by calculating the weighted average variance of similar studies as recommended in the Cochrane Handbook (section 16.1.3.1) [25].

Due to heterogeneity among studies, a random-effects model was fitted with mean as outcome using restricted maximum likelihood estimation (REML) in metafor package (version 1.9-9) in R [Version 3.3.3 (2017-03-06)] software to acquire a pooled mean estimate. As the number of studies is adequate, normal distribution was used to obtain a $95 \%$ confidence interval (CI) for the overall effect [23].

\section{Quality assessment}

Quality assessment was carried out according to the quality assessment tool for observational and cross-sectional studies of the National Heart, Lung and Blood Institute (NHLBI) [26] by two researchers $(\mathrm{CvdB}, \mathrm{JW})$ and reviewed by the other researcher (Online Resource 14).

\section{Results}

\section{Search results}

In total, we identified 1416 references, of which 62 papers fulfilled inclusion criteria for this systematic review (Fig. 1). Three hundred and one references were assessed during a search update.

\section{Description of the geriatric rehabilitation population}

The 62 papers included a total of 19,127 geriatric rehabilitation patients from 4 continents. The majority of studies were conducted in Europe $(n=26)$ followed by Asia $(n=19)$, Australia/New Zealand $(n=13)$, North America $(n=3)$ and South America $(n=1)$ [27]. Study size varied between 20 [27, 28] and 2650 [29] participants. The mean age of the geriatric rehabilitation study population ranged between 72 [30] and 85.4 [31, 32] years. Some studies focused on rehabilitation for a specific main diagnosis, such as hip fracture $(n=12)$, cardiac disease $(n=4)$, pulmonary disease $(n=3)$ or stroke $(n=4)$. However, most studies $(n=26)$ included more heterogeneous study populations with a wide array of diagnoses, most of which are highly prevalent in old age. Additionally, 13 studies did not provide the leading disease diagnosis. The length of stay in geriatric rehabilitation ranged between 10 [33] and 173 days (subgroup in Nishioka [34]). In only four studies, the mean length of stay was $\geq 60$ days [31, 34-36] (Online Resource 2). Not all 


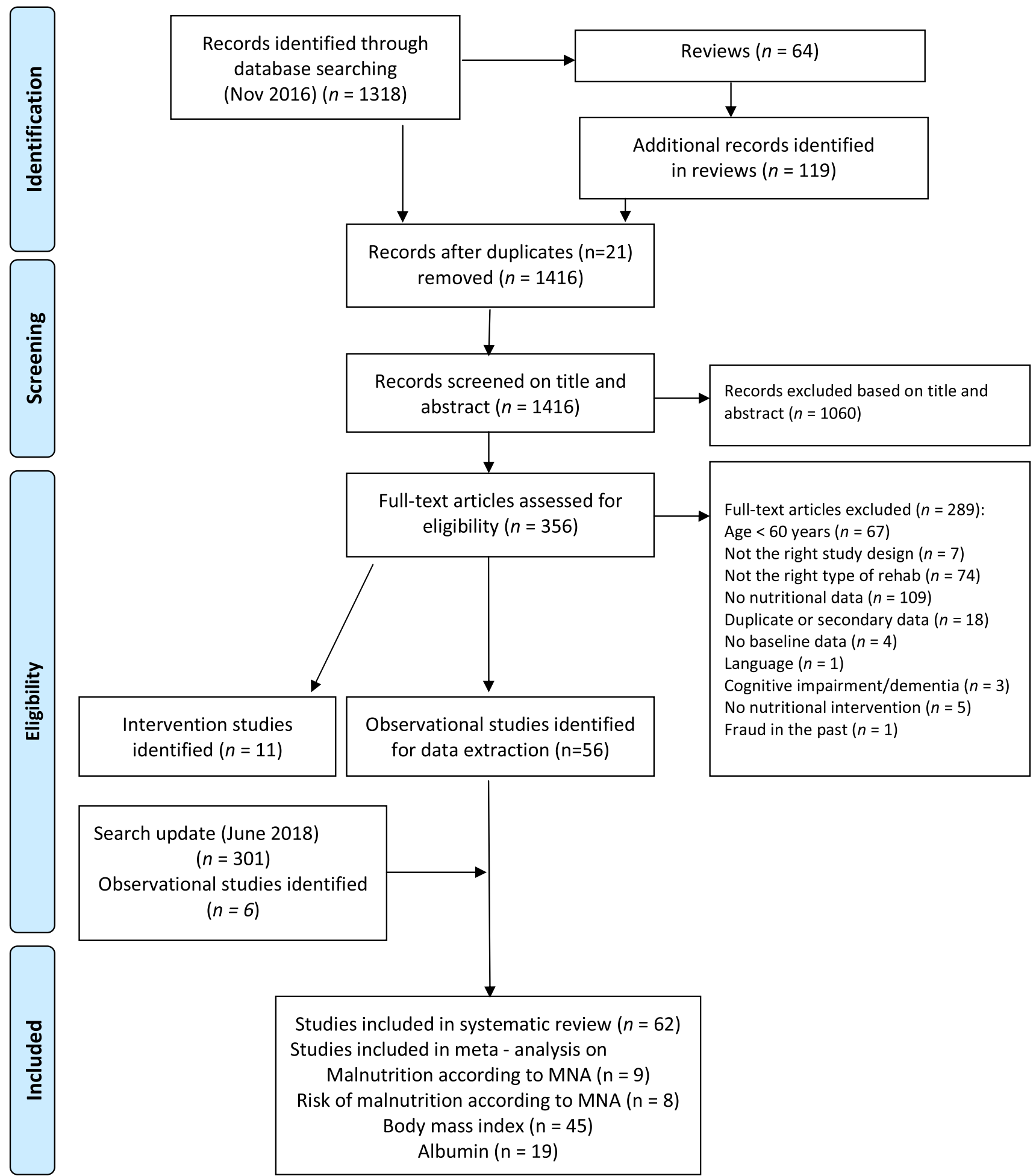

From: Moher D, Liberati A, Tetzlaff J, Altman DG, The PRISMA Group (2009). PLoS Med 6(7): e1000097. doi:10.1371/journal.pmed1000097

Fig. 1 Flow chart of screening and selection studies 
nutritional measurements reported in the included articles could be included in the present review, but they are listed in Online Resource 2.

\section{Nutritional status}

\section{Prevalence of malnutrition}

Malnutrition and risk of malnutrition were assessed by a variety of commonly used and also by some less established tools. Prevalence of malnutrition $(n=9)$ and risk of malnutrition $(n=8)$ according to the MNA $(0-16$ points and 17-23.5 points, respectively) were most often reported. Values ranged between 3\% [37] and 33\% [38] for malnutrition and between 28\% [39] and 58\% [30] for risk of malnutrition. A pooled estimate $(95 \% \mathrm{CI})$ indicated that on average $13(5-20) \%$ of geriatric rehabilitation patients were malnourished [30, 33, 37-43] and $47(40-54) \%$ were at risk of malnutrition [30, 33, 37-39, 41-43] according to the MNA (Figs. 2, 3). Prevalence of malnutrition and risk of malnutrition according to other screening tools $(n=19)$ ranged between 6\% [37] and 88\% [44] (Online Resource $3)$.

\section{Body mass index (BMI)}

A pooled estimate per continent $[27,28,30-33,35-39$, 41-74] showed the lowest mean (95\% CI) BMI in Eastern Asia with $21.1(20.3-21.9) \mathrm{kg} / \mathrm{m}^{2}(n=13)$ followed by Europe $24.6(23.9-25.2) \mathrm{kg} / \mathrm{m}^{2}(n=16)$ and Australia 25.6 (24.8-26.3) kg/m $(n=10)$ (Fig. 4). Prevalence of underweight according to the WHO standards $(<18.5$ or $19 \mathrm{~kg}$ ) $\mathrm{m}^{2}$ ) ranged between $0 \%$ [51] and $17 \%$ [61]. According to age-specific cutoff points, reflecting current expert opinions, prevalence of underweight $\left(<20 \mathrm{~kg} / \mathrm{m}^{2}\right)$ was $21 \%$ [28]. No study reported the prevalence of obesity $(\geq 30 \mathrm{~kg}$ / $\mathrm{m}^{2}$ ) (Table 1).

\section{Biochemical nutritional status markers}

Albumin was the most frequently reported blood marker that was presented in 25 studies. Mean $(95 \% \mathrm{CI})$ pooled estimate of albumin was $34.1(32.9-35.4) \mathrm{g} / \mathrm{L}[28,32,35-37$, 40-42, 45-47, 50, 52-54, 56, 58, 59, 66, 69, 75, 76] (Online Resource 4). Prevalence of reduced albumin levels $(n=5)$ ranged between $10.4 \%(\leq 30 \mathrm{~g} / \mathrm{L})[77]$ and $100 \%(<37 \mathrm{~g} / \mathrm{L})$ [56]. Prevalence of vitamin D deficiency according to

\section{MNA - Random effect}

Charlton et al., 2010

Chevalier et al., 2008

Eyigor et al., 2015

Guerini et al., 2010

Kaur et al., 2008

Neumann et al., 2005

O'Leary et al., 2011

Shum et al., 2005

Visvanathan et al., 2004
$11.70 \% \quad 0.33[0.31,0.35]$

$11.62 \% \quad 0.03[0.01,0.06]$

$11.76 \% \quad 0.05[0.04,0.07]$

$11.62 \% \quad 0.12[0.09,0.14]$

$11.60 \% \quad 0.05[0.02,0.08]$

$11.47 \% \quad 0.06[0.02,0.10]$

$10.82 \% \quad 0.06[-0.01,0.12]$

$10.18 \% \quad 0.17[0.09,0.25]$

$9.23 \% \quad 0.29[0.18,0.40]$

RE Model for all Studies $\left(Q=592.85, \mathrm{df}=8, \mathrm{p}=0.00 ; \mathrm{I}^{2}=98.3 \%\right)$

$100.00 \% \quad 0.13[0.05,0.20]$

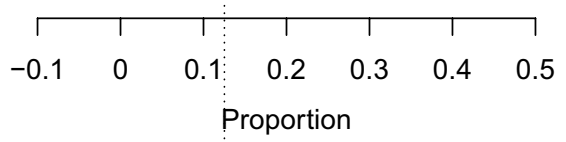

Fig. 2 Pooled prevalence of malnutrition in geriatric rehabilitation patients according to Mini Nutritional Assessment in a random-effects model 
MNA - Random effect

Charlton et al., 2010

Chevalier et al., 2008
$\mathrm{H}_{\mathrm{H}}$

Eyigor et al., 2015

Kaur et al., 2008

Neumann et al., 2005

O'Leary et al., 2011

Shum et al., 2005

Visvanathan et al., 2004

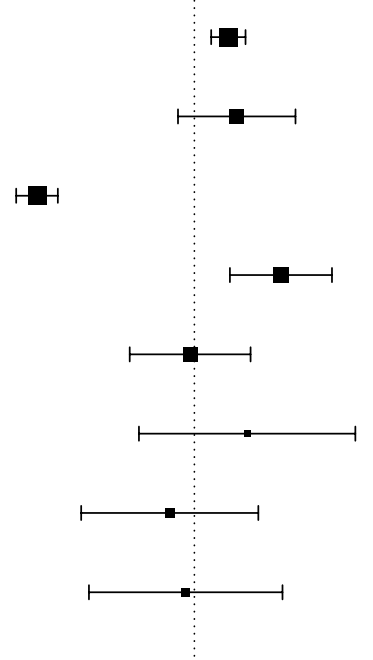

RE Model for all Studies $\left(Q=225.93, d f=7, p=0.00 ; 1^{2}=93.5 \%\right)$
$14.76 \% \quad 0.51[0.49,0.54]$

$12.95 \% \quad 0.53[0.45,0.60]$

$14.67 \% \quad 0.28[0.25,0.30]$

$13.39 \% \quad 0.58[0.52,0.64]$

$12.85 \% \quad 0.47[0.39,0.54]$

$9.80 \% \quad 0.54[0.40,0.67]$

$11.06 \% \quad 0.44[0.33,0.55]$

$10.53 \% \quad 0.46[0.34,0.58]$

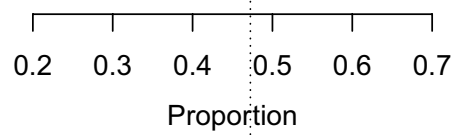

Fig. 3 Pooled prevalence of risk of malnutrition in geriatric rehabilitation patients according to Mini Nutritional Assessment in a random-effects model

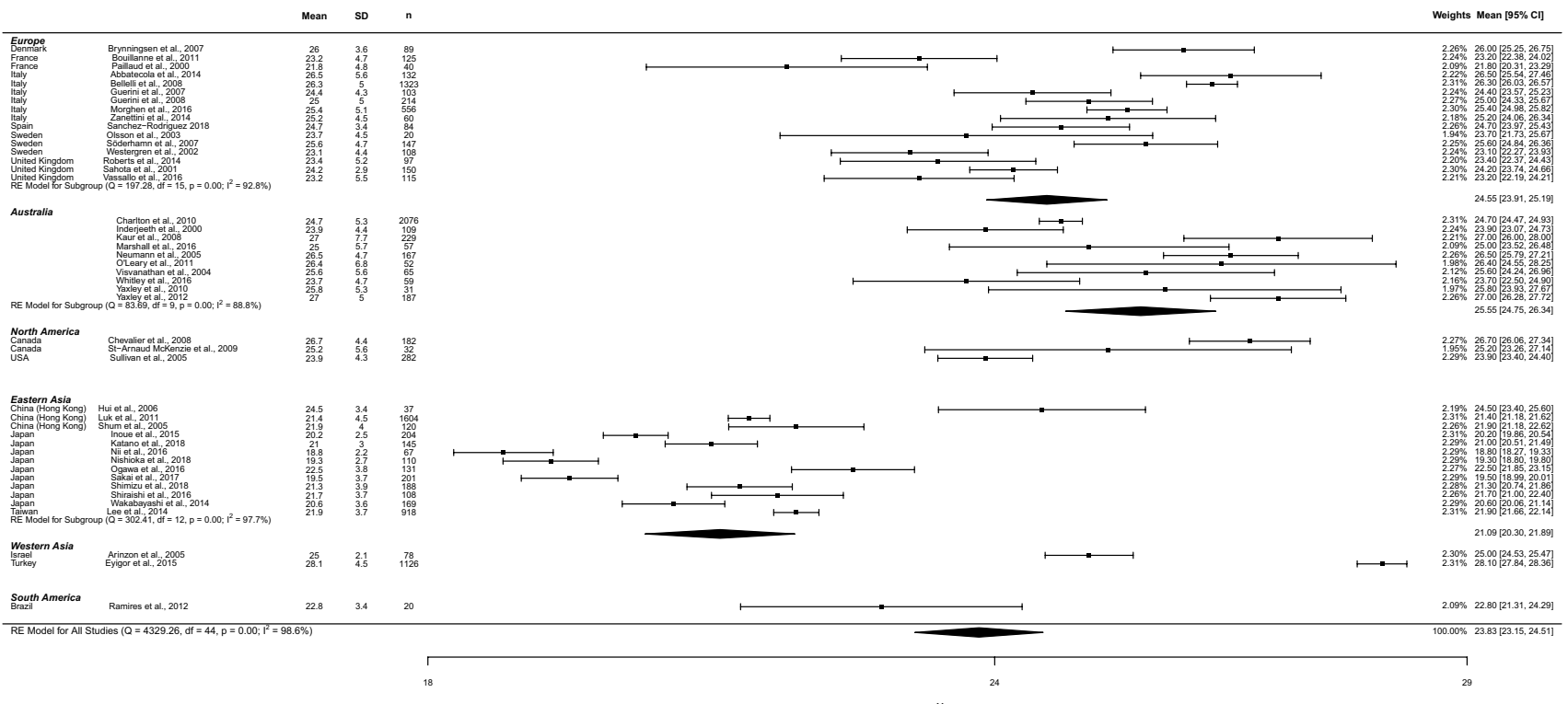

Fig. 4 Pooled average of body mass index $\left(\mathrm{kg} / \mathrm{m}^{2}\right)$ of geriatric rehabilitation patients by continents in a random-effects model 


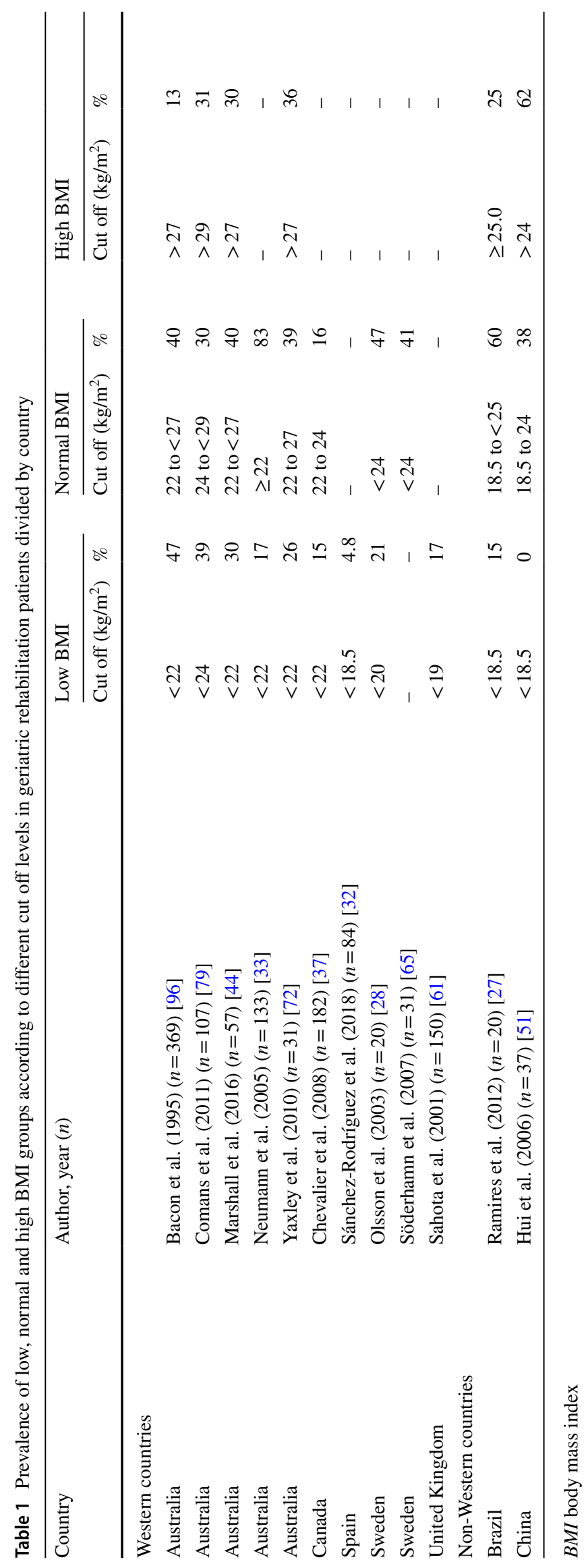


established cut off values $(<25 \mathrm{nmol} / \mathrm{L}$ or $<50 \mathrm{nmol} / \mathrm{L})$ was not reported, but one study reported a prevalence of reduced vitamin D (<28 nmol/L) in 67\% [52] (Online Resource 5). Micronutrient blood levels are shown in Online Resource 6.

\section{Nutritional intake}

Energy intake varied between $1260.4 \pm 387.8$ [63] and $2048 \pm 524 \mathrm{kcal}[41]$ [mean \pm standard deviation (SD)] and 22.8 (9.0) [54] and 33.2 (10.6) kcal/kg body weight (bw) per day [36] [median interquartile range (IQR)]. Protein intake (mean \pm SD) ranged from $43.5 \pm 13.7$ [63] to $88 \pm 21 \mathrm{~g}$ per day [41] and was $0.98 \pm 0.27 \mathrm{~g} / \mathrm{kg}$ body weight per day in the only study [66] that reported protein intake related to body weight. There was no information available on the prevalence of low energy or protein intake that would have reflected any available cut offs for these two parameters. Data on energy and macronutrient intake are shown in Online Resource 7, micronutrients intakes are shown in Online Resource 6.

\section{Muscle strength and function}

Handgrip strength was most commonly measured and values ranged between $11.8 \pm 6.7$ [53] and $26.3 \pm 6.5$ [58] kg (mean $\pm \mathrm{SD}$ ). Although this parameter is gender specific, only one study differentiated between men and women. There were no data available that reported the prevalence of reduced handgrip strength. An overview of handgrip strength values and other strength measurements is presented in Online Resource 8.

Muscle function was assessed in 17 studies (Online Resource 9). A high risk of falls according to Tinetti $(<19$ points) was prevalent in 62\% [29] of geriatric rehabilitation patients and according to the Physical Performance Test $(<8$ points) in $28 \%$ [78]. Balance problems according to the Romberg scale were prevalent in $42 \%$ [79] of the patients.

\section{Functional status}

In total, 39 studies reported on ADL or IADL (Online Resource 10). The most commonly applied tool was the Barthel Index (BI). BI scores ranged between $19.8 \pm 0.3$ and $92 \pm 7.7$ points (mean \pm SD). Most studies reported a BI between $42.4 \pm 21.6$ and $65.5 \pm 26.3$ points (mean $\pm S D$ ) representing a reduced functional status (Online Resource 10). The total Functional Independence Measure (FIM) score had a broad range between 56 (43.5) [36] and 88.5 (41.0) points [63] (median (IQR). The Katz ADL score and the Lawton Brody IADL score ranged from $2.6 \pm 1.9[78,80]$ to $3.9 \pm 1.9$ points [35] and from $1.7 \pm 1.8$ [55] to $4.8 \pm 2.6$ points [80] (mean $\pm \mathrm{SD}$ ), respectively, indicating reduced status of ADL and IADL.

\section{Body composition, sarcopenia and frailty}

Body composition was measured in ten studies with bioelectrical impedance analysis (BIA) or dual-energy X-ray absorptiometry (DEXA) (Online Resource 11). Only five of ten studies represented gender-specific data on body composition. The prevalence of reduced muscle mass was described only by one study which reported a reduced SMMI (women $<5.4 \mathrm{~kg} / \mathrm{m}^{2}$, men $<7.0 \mathrm{~kg} / \mathrm{m}^{2}$ ) in $42.3 \%$ of women and $57.7 \%$ of men [63]. The prevalence of sarcopenia was reported in two studies and was $76.1 \%$ [62] according to the consensus definition of the Asian working group for sarcopenia and 40\% (34\% men, $46 \%$ women) [73] according to reduced fat-free mass index and quadriceps strength. Prevalence of frailty according to Fried was reported in one study [39]; $14.8 \%$ were frail and $55.6 \%$ prefrail.

\section{Association between nutritional status and functional status}

The association between nutritional status (MNA or MNASF) and functional parameters (BI or FIM) was analyzed in ten studies (Online Resource 12). Seven [31, 33, 34, 69, $76,81,82]$ out of ten studies reported a significant association between either low MNA or low MNA-SF and low BI or low FIM. One study [30] did not show an association and in two studies $[54,64]$ heterogeneous outcomes were observed. Higher BMI values (in the normal to overweight range) were significantly associated with higher scores of the BI [68] and the FIM [64] in one study each. However, five $[31,54,57,66,69]$ out of seven studies did not indicate significant associations between BMI and either BI or FIM (Online Resource 13).

\section{Discussion}

The aim of this systematic literature review and metaanalysis was to present an overview of the nutritional status on admission and its association with functional parameters in geriatric rehabilitation patients. The pooled prevalence $(95 \% \mathrm{CI})$ for MNA (nine studies) demonstrated that malnutrition and risk of malnutrition were present in $13 \%$ (5-20) and 47\% (40-54) of the geriatric rehabilitation population, whereas the pooled estimate $(95 \% \mathrm{CI})$ of BMI $(n=45)$ was $23.8 \mathrm{~kg} / \mathrm{m}^{2}(23.2-24.5)$. The ranges of the values and heterogeneity were high among the individual studies of the respective pooled estimates. Malnutrition 
and risk of malnutrition according to MNA or MNA-SF were significantly associated with lower levels of BI and FIM in the majority of studies (seven out of ten) reporting it, whereas significant associations between BMI and BI or FIM were observed in only two out of seven studies.

The high pooled prevalence of malnutrition and risk of malnutrition according to MNA confirm earlier findings from a meta-analysis with slightly higher pooled prevalence $(95 \% \mathrm{CI})$ of $29 \%$ (22-37) for malnutrition and $49 \%$ (42-55) for risk of malnutrition [83]. However, heterogeneity was high, which limits the interpretation of these results. Compared to other settings, the prevalence of malnutrition (MNA) in geriatric rehabilitation is slightly lower than in hospital patients (18\%) and in nursing home residents (22\%), but higher than in the community-dwelling older people (3\%) [83]. In the included studies, a large variety of screening tools, e.g., MNA-SF, MUST, PG-SGA, with a large diversity in screening criteria was applied in addition to the MNA, which resulted in an even wider range of malnutrition prevalence (6-88\%). Our findings emphasize the need for a more standardized and age-specific approach towards nutritional screening in geriatric rehabilitation patients. Findings for the pooled estimates of BMI show that the vast majority of the geriatric rehabilitation population had mean BMI values in the normal or overweight range. BMI values were, as expected, lowest in Asia. Although mean BMI is normal, a considerable percentage (0-17\%) of the geriatric rehabilitation population had BMI values in the underweight range. Prevalence of obesity was not reported in any study. This would have been highly relevant information in this population, as obesity also has a relevant impact on functionality [7]. However, the high prevalence of malnutrition and risk of malnutrition combined with an average normal to high BMI indicates that a BMI is not a good proxy for malnutrition, and that screening for malnutrition with a validated screening tool should be used to identify those with malnutrition, and treat accordingly.

A wide range of indices for body composition were reported, but most studies applied bioelectrical impedance analysis. However, the high heterogeneity in body composition parameters does not allow an overall conclusion in this regard. Sarcopenia was addressed by only two studies that observed high prevalence (40-76\%) suggesting that low muscle mass is prevalent in the geriatric rehabilitation population. This is comparable to the prevalence reported in another systematic review, 56 (46-65) \% in rehabilitation inpatients [13]. It was higher than in communitydwelling seniors where the prevalence was $10 \%$ [84] but comparable to older medical patients with older age with prevalence rate up to $40 \%$ [85-87].

The pooled estimate of $34.1 \mathrm{~g} / \mathrm{L}$ for albumin indicates that a substantial part of the geriatric rehabilitation population has albumin levels below the reference range for healthy, non-malnourished individuals (35-45 g/L) [88]. We included albumin as it was indicated as a nutritional marker in the included studies. The value of albumin as a marker for nutritional status or malnutrition, however, is limited because of its sensitivity to inflammatory stress [89, 90]. Regarding nutrient intake, data were limited to a few studies that indicated that energy and protein intake, as well as vitamin D status, was low in the geriatric rehabilitation population. Information on micronutrient levels in blood was limited, indicating a knowledge gap in this aspect of nutritional status and potential unmet nutritional needs in this population.

We observed a positive association between nutritional status (MNA and MNA-SF) with functional status (BI and FIM). Our findings are in line with results observed in other patient groups $[8,9,20,91]$. Information on the association between BMI and functional status were contradictory. This might be because BMI and functional status showed a U- or $\mathrm{J}$-shaped curve in other populations with optimal BMI values between 20 and $30 \mathrm{~kg} / \mathrm{m}^{2}$ [92].

Our findings emphasize that in addition to malnutrition screening, screening for sarcopenia would benefit this population as a structured approach to manage malnutrition and muscle loss could improve muscle mass and functional outcomes [93]. It is also known that a higher protein intake (1.0-1.2 $\mathrm{g} / \mathrm{kg}$ bw/day) and an adequate energy intake can prevent disability in higher age [3].

Screening should be followed by an appropriate dietary intervention in geriatric rehabilitation patients, focusing on age-specific energy and protein recommendations and treatment of vitamin D deficiency where necessary. This approach may allow patients to regain muscle mass and muscle strength which will enhance functional recovery. However, this is also a field for further research as high-quality studies are scarce.

The quality of reporting on measurements was high in most included studies. The applied measurement tools were objective, reliable and valid as this was a selection criterion for nutritional outcome measurements. Potential confounders were considered in statistical analysis in onethird of the studies. Limitations in study quality were seen for sample size calculation, description of the study population and consideration of potential confounders.

One of the strengths of our systematic review is the comprehensive inclusion of data on the geriatric rehabilitation populations around the world in a systematic selection and review process according to the PRISMA guideline, based on a study protocol with predefined inclusion and exclusion criteria. The primary literature search was not limited by publication year. We focused on both nutritional and functional status and add relevant information to the current knowledge of the characteristics of geriatric rehabilitation patients. 
This review also has several limitations. Eligible studies had to report at least on nutritional status. This implies that the present paper does not provide a complete overview on functional status in geriatric rehabilitation patients. A further limitation is the MNA as the only malnutrition screening tool in the meta-analysis due to scarce data for other malnutrition screening tools like the new ESPEN and Global Leadership Initiative on Malnutrition (GLIM) tools $[94,95]$. In particular, the prevalence of ESPEN and GLIM malnutrition is a highly relevant topic for future research. The large heterogeneity of geriatric rehabilitation settings across the world often lacking a clear description may be seen as another limitation. Our findings therefore show that geriatric rehabilitation has not been clearly defined yet.

\section{Conclusions}

A relevant percentage of the geriatric rehabilitation population is affected by malnutrition and risk of malnutrition, vitamin $\mathrm{D}$ deficiency and low protein intake. The majority of geriatric rehabilitation patients have BMI values in the normal or overweight range. Malnutrition is associated with a low functional status. These findings emphasize the need for malnutrition screening followed by appropriate dietary interventions in geriatric rehabilitation patients. The latter should focus on age-specific energy and protein recommendations and treatment of vitamin $\mathrm{D}$ deficiency where necessary. This approach may allow patients to regain muscle mass and muscle strength which will enhance functional recovery. Future studies in this field should include a standardized set of nutritional and functional parameters to facilitate data comparison.

Acknowledgements Open Access funding provided by Projekt DEAL.

Funding This study was supported by Danone Nutricia Research.

\section{Compliance with ethical standards}

Conflict of interest There are conflicts of interest related to the manuscript: JvW, CVDB, ACY, YL are employees of Danone Nutricia Research; JW and RD report grants from Danone Nutricia, outside the submitted work; JB reports personal fees from Fresenius, Nestlé, Novartis, Pfizer, Bayer, and grants and personal fees from Danone Nutricia, outside the submitted work.

Ethical approval Not applicable.

Informed consent Not applicable.

Open Access This article is licensed under a Creative Commons Attribution 4.0 International License, which permits use, sharing, adaptation, distribution and reproduction in any medium or format, as long as you give appropriate credit to the original author(s) and the source, provide a link to the Creative Commons licence, and indicate if changes were made. The images or other third party material in this article are included in the article's Creative Commons licence, unless indicated otherwise in a credit line to the material. If material is not included in the article's Creative Commons licence and your intended use is not permitted by statutory regulation or exceeds the permitted use, you will need to obtain permission directly from the copyright holder. To view a copy of this licence, visit http://creativecommons .org/licenses/by/4.0/.

\section{References}

1. Bauer J, Biolo G, Cederholm T, Cesari M, Cruz-Jentoft AJ, Morley JE et al (2013) Evidence-based recommendations for optimal dietary protein intake in older people: a position paper from the PROT-AGE Study Group. J Am Med Direc Assoc 14(8):542-559

2. Kruizenga $H$, van Keeken S, Weijs P, Bastiaanse L, Beijer S, Huisman-de Waal G et al (2016) Undernutrition screening survey in 564,063 patients: patients with a positive undernutrition screening score stay in hospital $1.4 \mathrm{~d}$ longer. Am J Clin Nutr 103(4):1026-1032

3. Mendonca N, Granic A, Hill TR, Siervo M, Mathers JC, Kingston A et al (2019) Protein Intake and disability trajectories in very old adults: the Newcastle $85+$ study. J Am Geriatr Soc 67(1):50-56

4. Volkert D, Beck AM, Cederholm T, Cruz-Jentoft A, Goisser S, Hooper L et al (2019) ESPEN guideline on clinical nutrition and hydration in geriatrics. Clin Nutr 38(1):10-47

5. Misu S, Asai T, Doi T, Sawa R, Ueda Y, Saito T et al (2017) Association between gait abnormality and malnutrition in a community-dwelling elderly population. Geriatr Gerontol Int 17(8):1155-1160

6. Naseer M, Forssell H, Fagerstrom C (2016) Malnutrition, functional ability and mortality among older people aged 60 years: a 7-year longitudinal study. Eur J Clin Nutr 70(3):399-404

7. Trevisan C, Crippa A, Ek S, Welmer AK, Sergi G, Maggi S et al (2019) Nutritional status, body mass index, and the risk of falls in community-dwelling older adults: a systematic review and meta-analysis. J Am Med Direc Assoc 20(5):569-582

8. Goisser S, Schrader E, Singler K, Bertsch T, Gefeller O, Biber $\mathrm{R}$ et al (2015) Malnutrition according to mini nutritional assessment is associated with severe functional impairment in geriatric patients before and up to 6 months after hip fracture. J Am Med Dir Assoc 16(8):661-667

9. Kaiser R, Winning K, Uter W, Volkert D, Lesser S, Stehle P et al (2010) Functionality and mortality in obese nursing home residents: an example of 'risk factor paradox'? J Am Med Dir Assoc 11(6):428-435

10. Shen Y, Chen J, Chen X, Hou L, Lin X, Yang M (2019) Prevalence and associated factors of sarcopenia in nursing home residents: a systematic review and meta-analysis. J Am Med Dir Assoc 20(1):5-13

11. Grund S, Gordon AL, van Balen R, Bachmann S, Cherubini A, Landi F et al (2019) European consensus on core principles and future priorities for geriatric rehabilitation: consensus statement. Eur Geriatr Med:1-6

12. Cederholm T, Barazzoni R, Austin P, Ballmer P, Biolo G, Bischoff SC et al (2017) ESPEN guidelines on definitions and terminology of clinical nutrition. Clin Nutr 36(1):49-64 
13. Churilov I, Churilov L, MacIsaac RJ, Ekinci EI (2018) Systematic review and meta-analysis of prevalence of sarcopenia in post acute inpatient rehabilitation. Osteoporos Int 29(4):805-812

14. Morley JE, Vellas B, van Kan GA, Anker SD, Bauer JM, Bernabei R et al (2013) Frailty consensus: a call to action. J Am Med Dir Assoc 14(6):392-397

15. Bachmann S, Finger C, Huss A, Egger M, Stuck AE, CloughGorr KM (2010) Inpatient rehabilitation specifically designed for geriatric patients: systematic review and meta-analysis of randomised controlled trials. BMJ 340:c1718

16. van Balen R, Gordon AL, Schols JM, Drewes YM, Achterberg WP (2019) What is geriatric rehabilitation and how should it be organized? A Delphi study aimed at reaching European consensus. Eur Geriatr Med 10(6):977-987

17. Grund S, van Wijngaarden JP, Gordon AL, Schols JM, Bauer JM (2019) EuGMS survey on structures of geriatric rehabilitation across Europe. Eur Geriatr Med:1-16

18. Malafarina $\mathrm{V}$, Reginster JY, Cabrerizo $\mathrm{S}$, Bruyère $\mathrm{O}$, Kanis JA, Martinez JA et al (2018) Nutritional status and nutritional treatment are related to outcomes and mortality in older adults with hip fracture. Nutrients 10(5):555

19. Rahman A, Jafry S, Jeejeebhoy K, Nagpal AD, Pisani B, Agarwala R (2016) Malnutrition and Cachexia in Heart Failure. JPEN J Parenter Enteral Nutr 40(4):475-486

20. Smoliner C, Sieber CC, Wirth R (2014) Prevalence of sarcopenia in geriatric hospitalized patients. J Am Med Dir Assoc 15(4):267-272

21. Liberati A, Altman DG, Tetzlaff J, Mulrow C, Gotzsche PC, Ioannidis JP et al (2009) The PRISMA statement for reporting systematic reviews and meta-analyses of studies that evaluate health care interventions: explanation and elaboration. J Clin Epidemiol 62(10): $1-34$

22. Moher D, Liberati A, Tetzlaff J, Altman DG (2009) Preferred reporting items for systematic reviews and meta-analyses: the PRISMA statement. J Clin Epidemiol 62(10):1006-1012

23. Viechtbauer $\mathrm{W}$ (2010) Conducting meta-analyses in $\mathrm{R}$ with the metafor package. J Stat Softw 36(3):1-48

24. Team RC (2019) A language and environment for statistical computing 2019. https://www.R-project.org/. Accessed 25 Mar 2019

25. Cochrane Handbook for Systematic Reviews of Interventions (2011) The Cochrane Collaboration version 5.1.0 (updated March 2011)

26. National Heart Lung, and Blood Institute (2019) Quality assessment tool for observational cohort and cross-sectional studies [updated January 3, 2019]. https://www.nhlbi.nih.gov/healt h-topics/study-quality-assessment-tools. Accessed on 4 Jul 2017

27. Ramires BR, de Oliveira EP, Pimentel GD, McLellan KCP, Nakato DM, Faganello MM et al (2012) Resting energy expenditure and carbohydrate oxidation are higher in elderly patients with COPD: a case control study. Nutr J 11:37

28. Olsson E, Karlström B (2003) Body composition, dietary intake and estimated energy expenditure in female patients on geriatric rehabilitation wards. Scand J Nutr 47(4):179-187

29. Ghisla MK, Cossi S, Timpini A, Baroni F, Facchi E, Marengoni A (2007) Predictors of successful rehabilitation in geriatric patients: subgroup analysis of patients with cognitive impairment. Aging Clin Exp Res 19(5):417-423

30. Kaur S, Miller MD, Halbert J, Giles LC, Crotty M (2008) Nutritional status of adults participating in ambulatory rehabilitation. Asia Pac J Clin Nutr 17(2):199-207

31. Nishioka S, Wakabayashi H, Momosaki R (2018) Nutritional status changes and activities of daily living after hip fracture in convalescent rehabilitation units: a retrospective observational cohort study from the Japan Rehabilitation Nutrition Database. J Acad Nutr Diet 118(7):1270-1276
32. Sanchez-Rodriguez D, Marco E, Ronquillo-Moreno N, MacielBravo L, Gonzales-Carhuancho A, Duran X et al (2018) ASPEN-AND-ESPEN: a postacute-care comparison of the basic definition of malnutrition from the American Society of Parenteral and Enteral Nutrition and Academy of Nutrition and Dietetics with the European Society for Clinical Nutrition and Metabolism definition. Clin Nutr 38(1):297-302

33. Neumann SA, Miller MD, Daniels L, Crotty M (2005) Nutritional status and clinical outcomes of older patients in rehabilitation. J Hum Nutr Diet 18(2):129-136

34. Nishioka S, Wakabayashi H, Nishioka E, Yoshida T, Mori N, Watanabe R (2016) Nutritional improvement correlates with recovery of activities of daily living among malnourished elderly stroke patients in the convalescent stage: a cross-sectional study. J Acad Nutr Diet 116(5):837-843

35. Bouillanne O, Hay P, Liabaud B, Duché C, Cynober L, Aussel C (2011) Evidence that albumin is not a suitable marker of body composition-related nutritional status in elderly patients. Nutrition 27(2):165-169

36. Nii M, Maeda K, Wakabayashi H, Nishioka S, Tanaka A (2016) Nutritional improvement and energy intake are associated with functional recovery in patients after cerebrovascular disorders. J Stroke Cerebrovasc Dis 25(1):57-62

37. Chevalier S, Saoud F, Gray-Donald K, Morais JA (2008) The physical functional capacity of frail elderly persons undergoing ambulatory rehabilitation is related to their nutritional status. J Nutr Health Aging 12(10):721-726

38. Charlton KE, Nichols C, Bowden S, Lambert K, Barone L, Mason M et al (2010) Older rehabilitation patients are at high risk of malnutrition: evidence from a large Australian database. J Nutr Health Aging 14(8):622-628

39. Eyigor S, Kutsal YG, Duran E, Huner B, Paker N, Durmus B et al (2015) Frailty prevalence and related factors in the older adult-FrailTURK Project. Age (Dordr) 37(3):9791

40. Guerini F, Frisoni GB, Morghen S, Speciale S, Bellelli G, Trabucchi M (2010) Clinical instability as a predictor of negative outcomes among elderly patients admitted to a rehabilitation ward. J Am Med Dir Assoc 11(6):443-448

41. O'Leary F, Flood VM, Petocz P, Allman-Farinelli M, Samman S (2011) B vitamin status, dietary intake and length of stay in a sample of elderly rehabilitation patients. J Nutr Health Aging 15(6):485-489

42. Shum NC, Hui WWH, Chu FCS, Chai J, Chow TW (2005) Prevalence of malnutrition and risk factors in geriatric patients of a convalescent and rehabilitation hospital. Hong Kong Med J 11(4):234-242

43. Visvanathan R, Penhall R, Chapman I (2004) Nutritional screening of older people in a sub-acute care facility in Australia and its relation to discharge outcomes. Age Ageing 33(3):260-265

44. Marshall S, Young A, Bauer J, Isenring E (2016) Nutrition Screening in Geriatric Rehabilitation: Criterion (Concurrent and Predictive) Validity of the Malnutrition Screening Tool and the Mini Nutritional Assessment-Short Form. J Acad Nutr Diet 116(5):795-801

45. Abbatecola AM, Fumagalli A, Spazzafumo L, Betti V, Misuraca C, Corsonello A et al (2014) Body composition markers in older persons with COPD. Age Ageing 43(4):548-553

46. Arinzon Z, Fidelman Z, Zuta A, Peisakh A, Berner YN (2005) Functional recovery after hip fracture in old-old elderly patients. Arch Gerontol Geriatr 40(3):327-336

47. Bellelli G, Magnifico F, Trabucchi M (2008) Outcomes at 12 months in a population of elderly patients discharged from a rehabilitation unit. J Am Med Direc Assoc 9(1):55-64 
48. Brynningsen PK, Damsgaard EMS, Husted SE (2007) Improved nutritional status in elderly patients 6 months after stroke. J Nutr Health Aging 11(1):75-79

49. Guerini F, Frisoni GB, Bellelli G, Trabucchi M (2007) Subcortical vascular lesions and functional recovery in older patients with gait disorders. Arch Gerontol Geriatr 45(1):87-96

50. Guerini F, Frisoni GB, Marrè A, Turco R, Bellelli G, Trabucchi M (2008) Subcortical vascular lesions predict falls at 12 months in elderly patients discharged from a rehabilitation ward. Arch Phys Med Rehabil 89(8):1522-1527

51. Hui E, Yang H, Chan LS, Or K, Lee DTF, Yu CM et al (2006) A community model of group rehabilitation for older patients with chronic heart failure: a pilot study. Disabil Rehabil 28(23):1491-1497

52. Inderjeeth CA, Nicklason F, Al-Lahham Y, Greenaway TM, Jones G, Parameswaran VV et al (2000) Vitamin D deficiency and secondary hyperparathyroidism: clinical and biochemical associations in older non-institutionalised Southern Tasmanians. Aust N Z J Med 30(2):209-214

53. Inoue T, Misu S, Tanaka T, Sakamoto H, Iwata K, Chuman Y et al (2017) Pre-fracture nutritional status is predictive of functional status at discharge during the acute phase with hip fracture patients: a multicenter prospective cohort study. Clin Nutr 36(5):1320-1325

54. Katano S, Hashimoto A, Ohori K, Watanabe A, Honma R, Yanase $R$ et al (2018) Nutritional status and energy intake as predictors of functional status after cardiac rehabilitation in elderly inpatients with heart failure- a retrospective cohort study. Circ J 82(6):1584-1591

55. Lee W-J, Chou M-Y, Peng L-N, Liang C-K, Liu L-K, Liu C-L et al (2014) Predicting clinical instability of older patients in post-acute care units: a nationwide cohort study. Geriatr Gerontol Int 14(2):267-272

56. Luk JK, Chiu PK, Tam S, Chu LW (2011) Relationship between admission albumin levels and rehabilitation outcomes in older patients. Arch Gerontol Geriatr 53(1):84-89

57. Morghen S, Morandi A, Guccione AA, Bozzini M, Guerini F, Gatti R et al (2017) The association between patient participation and functional gain following inpatient rehabilitation. Aging Clin Exp Res 29(4):729-736

58. Ogawa M, Izawa KP, Satomi-Kobayashi S, Kitamura A, Ono $\mathrm{R}$, Sakai Y et al (2017) Poor preoperative nutritional status is an important predictor of the retardation of rehabilitation after cardiac surgery in elderly cardiac patients. Aging Clin Exp Res 29(2):283-290

59. Paillaud E, Bories PN, Le Parco JC, Campillo B (2000) Nutritional status and energy expenditure in elderly patients with recent hip fracture during a 2-month follow-up. Br J Nutr 83(2):97-103

60. Roberts HC, Syddall HE, Sparkes J, Ritchie J, Butchart J, Kerr A et al (2014) Grip strength and its determinants among older people in different healthcare settings. Age Ageing 43(2):241-246

61. Sahota O, Gaynor K, Harwood RH, Hosking DJ (2001) Hypovitaminosis D and 'functional hypoparathyroidism'-the NoNoF (Nottingham Neck of Femur) study. Age Ageing 30(6):467-472

62. Sakai K, Nakayama E, Tohara H, Kodama K, Takehisa T, Takehisa $\mathrm{Y}$ et al (2017) Relationship between tongue strength, lip strength, and nutrition-related sarcopenia in older rehabilitation inpatients: a cross-sectional study. Clin Interv Aging 12:1207-1214

63. Shimizu A, Maeda K, Tanaka K, Ogawa M, Kayashita J (2018) Texture-modified diets are associated with decreased muscle mass in older adults admitted to a rehabilitation ward. Geriatr Gerontol Int 18(5):698-704
64. Shiraishi A, Yoshimura Y, Wakabayashi H, Tsuji Y (2017) Poor oral status is associated with rehabilitation outcome in older people. Geriatr Gerontol Int 17(4):598-604

65. Soderhamn U, Bachrach-Lindstrom M, Ek AC (2007) Nutritional screening and perceived health in a group of geriatric rehabilitation patients. J Clin Nurs 16(11):1997-2006

66. St-Arnaud McKenzie D, Kergoat MJ, Dube L, Ferland G (2009) The evolution of nutritional status of geriatric patients without cachexia is associated with food intake in sub-acute care. J Nutr Health Aging 13(2):83-88

67. Sullivan DH, Roberson PK, Bopp MM (2005) Hypoalbuminemia 3 months after hospital discharge: significance for long-term survival. J Am Geriatr Soc 53(7):1222-1226

68. Vassallo M, Poynter L, Sharma JC, Kwan JSK (2016) Nutritional risk, body mass index and rehabilitation outcome in cognitively impaired vs. cognitively normal patients. Eur Geriatr Med 7(2):122-126

69. Wakabayashi H, Sashika H (2014) Malnutrition is associated with poor rehabilitation outcome in elderly inpatients with hospital-associated deconditioning a prospective cohort study. J Rehabil Med 46(3):277-282

70. Westergren A, Ohlsson O, Hallberg IR (2002) Eating difficulties in relation to gender, length of stay, and discharge to institutional care, among patients in stroke rehabilitation. Disabil Rehabil 24(10):523-533

71. Whitley A, Skliros E, Graven C, McIntosh R, Lasry C, Newsome C et al (2017) Changes in nutritional and functional status in longer stay patients admitted to a geriatric evaluation and management unit. J Nutr Health Aging 21(6):686-691

72. Yaxley A, Miller M, Masters S, Ahern M, Crotty M (2010) Body composition in older orthopaedic rehabilitation inpatients: are field methods valid? Nutr Diet 67(3):160-165

73. Yaxley A, Miller MD, Fraser RJ, Cobiac L, Crotty M (2012) The complexity of treating wasting in ambulatory rehabilitation: Is it starvation, sarcopenia, cachexia or a combination of these conditions? Asia Pac J Clin Nutr 21(3):386-393

74. Zanettini R, Gatto G, Mori I, Pozzoni MB, Pelenghi S, Martinelli L et al (2014) Cardiac rehabilitation and mid-term follow-up after transcatheter aortic valve implantation. J Geriatr Cardiol 11(4):279-285

75. Di Monaco M, Di Monaco R, Manca M, Cavanna A (2001) Serum albumin is an independent predictor of functional recovery after hip fracture: a retrospective study of 275 inpatients. In: Burckhardt P, Dawson-Hughes B, Heaney RP (eds) Nutritional aspects of osteoporosis. Academic Press, San Diego, pp 251-259

76. Miu KYD, Lam PS (2017) Effects of nutritional status on 6-month outcome of hip fractures in elderly patients. Ann Rehab Med 41(6):1005-1012

77. Friedman PJ, Campbell AJ, Caradoc-Davies TH (1985) Hypoalbuminaemia in the elderly is due to disease not malnutrition. $\mathrm{J}$ Clin Exp Gerontol 7(3):191-203

78. Rozzini R, Frisoni GB, Ferrucci L, Barbisoni P, Sabatini T, Ranieri $P$ et al (2002) Geriatric Index of comorbidity: validation and comparison with other measures of comorbidity. Age Ageing 31(4):277-285

79. Comans TA, Currin ML, Brauer SG, Haines TP (2011) Factors associated with quality of life and caregiver strain amongst frail older adults referred to a community rehabilitation service: implications for service delivery. Disabil Rehabil 33(13-14):1215-1221

80. Bertozzi B, Barbisoni P, Franzoni S, Rozzini R, Frisoni GB, Trabucchi M (1996) Factors related to length of stay in a geriatric evaluation and rehabilitation unit. Aging (Milano) 8(3):170-175

81. Goto R, Watanabe H, Tsutsumi M, Kanamori T, Maeno T, Yanagi $\mathrm{H}$ (2016) Factors associated with the recovery of activities 
of daily living after hospitalization for acute medical illness: a prospective cohort study. J Phys Ther Sci 28(10):2763-2768

82. Villafañe JH, Pirali C, Dughi S, Testa A, Manno S, Bishop MD et al (2016) Association between malnutrition and Barthel Index in a cohort of hospitalized older adults article information. J Phys Ther Sci 28(2):607-612

83. Cereda E, Pedrolli C, Klersy C, Bonardi C, Quarleri L, Cappello $S$ et al (2016) Nutritional status in older persons according to healthcare setting: a systematic review and meta-analysis of prevalence data using MNA(®). Clin Nutr 35(6):1282-1290

84. Shafiee G, Keshtkar A, Soltani A, Ahadi Z, Larijani B, Heshmat R (2017) Prevalence of sarcopenia in the world: a systematic review and meta- analysis of general population studies. J Diabetes Metab Disord 16:21

85. Dent E, Hoogendijk EO (2014) Psychosocial factors modify the association of frailty with adverse outcomes: a prospective study of hospitalised older people. BMC Geriatr 14:108

86. Gingrich A, Volkert D, Kiesswetter E, Thomanek M, Bach S, Sieber CC et al (2019) Prevalence and overlap of sarcopenia, frailty, cachexia and malnutrition in older medical inpatients. BMC Geriatr 19(1):120

87. Wesseltoft-Rao N, Hjermstad MJ, Ikdahl T, Dajani O, Ulven SM, Iversen PO et al (2015) Comparing two classifications of cancer cachexia and their association with survival in patients with unresected pancreatic cancer. Nutr Cancer 67(3):472-480

88. Gatta A, Verardo A, Bolognesi M (2012) Hypoalbuminemia. Int Emerg Med 7(Suppl 3):S193-S199

89. Kuzuya M, Izawa S, Enoki H, Okada K, Iguchi A (2007) Is serum albumin a good marker for malnutrition in the physically impaired elderly? Clin Nutr 26(1):84-90

90. Zhang Z, Pereira SL, Luo M, Matheson EM (2017) Evaluation of blood biomarkers associated with risk of malnutrition in older adults: a systematic review and meta-analysis. Nutrients 9(8):829

91. Kaburagi T, Hirasawa R, Yoshino H, Odaka Y, Satomi M, Nakano M et al (2011) Nutritional status is strongly correlated with grip strength and depression in community-living elderly Japanese. Public Health Nutr 14(11):1893-1899
92. Wojzischke J, Diekmann R, Bauer JM (2016) Obesity in old age and its importance for functionality and frailty. Z Gerontol Geriatr 49(7):573-580

93. Landi F, Camprubi-Robles M, Bear DE, Cederholm T, Malafarina $\mathrm{V}$, Welch AA et al (2019) Muscle loss: the new malnutrition challenge in clinical practice. Clin Nutr 38(5):2113-2120

94. Cederholm T, Bosaeus I, Barazzoni R, Bauer J, Van Gossum A, Klek S et al (2015) Diagnostic criteria for malnutrition-an ESPEN Consensus Statement. Clin Nutr 34(3):335-340

95. Cederholm T, Jensen GL, Correia M, Gonzalez MC, Fukushima R, Higashiguchi T et al (2019) GLIM criteria for the diagnosis of malnutrition-a consensus report from the global clinical nutrition community. J Cachexia Sarcopenia Muscle 10(1):207-217

96. Bacon J (1995) Famine in the midst of plenty: nutritional status of the frail elderly. In: Proceed Nutr Soc Aust, vol 19. Nutrition Society of Australia, pp 152-156

97. Di Monaco M, Vallero F, Di Monaco R et al (2004) Body composition and hip fracture type in elderly women. Clin Rheumatol 23(1):6-10

98. Di Monaco M, Vallero F, Di Monaco R et al (2006) 25-hydroxyvitamin $\mathrm{D}$, parathyroid hormone, and functional recovery after hip fracture in elderly patients. J Bone Miner Metab 24(1):42-47

99. Lee Y-S, Lin C-S, Jseng Y-H et al (2012) Predictive factors for patients discharged after participating in a post-acute care program. J Clin Gerontol Geriatr 3(1):25-28

100. Ranieri P, Rozzini R, Franzoni S et al (2001) One-year mortality in elderly stable patients with COPD. Monaldi Arch Chest Dis 56(6):481-485

101. Rolland Y, Pillard F, Lauwers-Cances V et al (2004) Rehabilitation outcome of elderly patients with hip fracture and cognitive impairment. Disabil Rehabil 26(7):425-431

Publisher's Note Springer Nature remains neutral with regard to jurisdictional claims in published maps and institutional affiliations. 